\title{
Spontaneous multiscale phase separation within fluorinated xerogel coatings for fouling-release surfaces
}

Anastasiya Sokolova , Joseph J. Bailey, Grant T. Waltz, Lenora H. Brewer, John A. Finlay, Jill Fornalik , Dean E. Wendt, Maureen E. Callow, James A. Callow, Frank V. Bright and Michael R. Detty

Four-component xerogel films consisting of 1 mole- $\%$-octadecyltrimethoxysilane (C18) and 50 mole- $\%$ tetraethoxysilane (TEOS) in combination with 1-24 mole- $\%$ tridecafluoro-1,1,2,2-tetrahydrooctyltriethoxysilane (TDF) and 25-48 mole-\% n-octyltriethoxysilane (C8) and a 1:49:50 mole-\% C18/TDF/TEOS were prepared. Settlement of barnacle cyprids and removal of juvenile barnacles, settlement of zoospores of the alga Ulva linza, and strength of attachment of 7-day sporelings (young plants) of Ulva were compared amongst the xerogel formulations. Several of the xerogel formulations were comparable to poly(dimethylsiloxane) elastomer with respect to removal of juvenile barnacles and removal of sporeling biomass. The 1:4:45:50 and 1:14:35:50 C18/TDF/C8/TEOS xerogels displayed some phase segregation by atomic force microscopy (AFM) pre- and post-immersion in water. Imaging reflectance infrared microscopy showed the formation of islands of alkane-rich and perfluoroalkane-rich regions in these same xerogels both pre- and post-immersion in water. Surface energies were unchanged upon immersion in water for $48 \mathrm{~h}$ amongst the TDF-containing xerogel coatings. AFM measurements demonstrated that surface roughness on the 1:4:45:50 and 1:14:35:50 C18/TDF/C8/TEOS xerogel coatings decreased upon immersion in water.

Keywords: biofouling; macrofouling; fouling release; topography; barnacle settlement; barnacle removal; Ulva zoospore settlement; Ulva sporeling removal; xerogels; perfluoroalkyl

\section{Introduction}

Biofouling on ships' hulls is a significant problem worldwide causing an increase in fuel consumption due to drag (Schultz 2007; Schultz et al. 2011) as well as mediating the spread of non-indigenous species (reviewed by Piola et al. 2009). The economic impact of biofouling has been estimated to be $\$ 56 \mathrm{M}$ per year (\$1B over 15 years) for a single class of naval vessel (Schultz et al. 2011). Biocides have been used in the past to combat biofouling, but the use of biocides in antifouling (AF) paints is becoming increasingly restricted (see Thomas and Brooks 2010).

Environmentally benign approaches to the control of biofouling integrate the biology/biochemistry of fouling and the role of surface characteristics of materials (for a review see Genzer and Efimenko 2006). The secretion, cross-linking or curing of bioadhesives produced by macrofouling organisms are areas of active research (Dickinson et al. 2009; Barlow et al. 2010; Gohad et al. 2010; Kamino 2010; Wilker 2010). Mechanisms of adhesive cross-linking/ curing include radical-mediated cross-linking, enzyme- catalyzed protein modification and cross-linking, and development of specific protein hierarchical structures (eg amyloid-like fibrils). The elastic modulus of surfaces influences the detachment mechanism of fouling organisms (Ramsay et al. 2008) and artificial systems such as "pseudobarnacles" (Brady and Singer 2000; Berglin et al. 2003; Kim et al. 2007). Materials with a low elastic modulus deform readily and release fouling organisms by peeling while rigid materials release organisms by shear.

Initially, non-biocidal commercial products were based on poly(dimethylsiloxane) elastomer (PDMSE), but newer commercial products effectively utilize fluorinated groups (Dobretsov and Thomason 2011). Historically, several fluoropolymers were considered as fouling-release (FR) coatings because of their low surface energies (Lindner 1992; Davis 1996; Brady 1997). However, the fluoropolymers rapidly fouled (Davis 1996; Brady 1997) perhaps due to a combination of low surface energies outside the $20-25 \mathrm{mN} \mathrm{m}^{-1}$ minimum range in the "Baier curve" where minimal bioadhesion has been reported (Baier et al. 1968; Baier 
1984), their non-elastomeric nature, and "rough" surfaces promoting adhesive interlocking. In some experimental coatings, blends of a fluorocarbon polymer with polysiloxanes, polystyrenes, and polyethylene glycols are being investigated and provide good performance in laboratory assays (eg Gudipati et al. 2005; Marabotti et al. 2009; Martinelli et al. 2009; Weinman et al. 2009). These materials have low surface energies in the dry state, but those based on amphiphilic polymers (eg Martinelli et al. 2008, 2011; Weinmann et al. 2009) reconstruct underwater, becoming more hydrophilic. These materials have low surface energies and low elastic-moduli promoting the peeling mechanism for FR (Brady and Singer 2000).

Fluorinated FR polymers based on blends of a fluorocarbon polymer with polysiloxanes, polystyrenes, and polyethylene glycols are expensive to produce and often the coatings are constructed in layers. Organically-modified, hybrid xerogel coatings have been shown to possess AF/FR characteristics (Tang et al. 2005; McMaster et al. 2009; Bennett et al. 2010; Finlay et al. 2010), are inexpensive to produce and have been applied to surfaces via spin coating, dip coating, spray coating, and brushing (Tang et al. 2005; Selvaggio et al. 2009). These coatings have a range of surface energies and include both hydrophilic and hydrophobic surfaces. Approximately 100 boats have been coated with an organically-modified, hybrid xerogel (AquaFast ${ }^{\mathbb{R}}$ ) and the same material has been used to minimize biofouling on the monitoring system of an underwater archaeological site (Selvaggio et al. 2009). The present authors recently described hybrid xerogel surfaces of $1-2-\mu \mathrm{m}$ thickness and low surface energy incorporating 1 mole- $\%$ of an $n$-octadecyltrimethoxysilane $(\mathrm{C} 18)$ precursor in combination with $n$ octyltriethoxysilane (C8) and tetraethoxysilane (TEOS) that released juvenile barnacles and sporelings (young plants) of Ulva efficiently (Gunari et al. 2011). These coatings displayed structural features on both the micrometer and nanometer scale as observed by imaging transmission infrared (IR) microscopy and atomic force microscopy (AFM) measurements.

The incorporation of fluoroalkane functionality within xerogel coatings is straightforward with the solgel process. Mixed alkane and perfluoroalkane modifications can be incorporated from appropriate perfluoroalkyl- and alkyltrialkoxysilane precursors. In this paper, surface segregation into nm- and/or $\mu \mathrm{m}$ scale structural features on surfaces containing hydrocarbon and fluorocarbon functionality from xerogel coatings prepared from sol precursors incorporating 1 mole- $\%$ C18 and 1-24 mole- $\%$ tridecafluorooctyltriethoxysilane (TDF) in combination with $\mathrm{C} 8$ and 50 mole- $\%$ TEOS is demonstrated. In this series, coatings with values of $\gamma_{\mathrm{S}}$ outside the $20-25 \mathrm{mN} \mathrm{m}^{-1}$ minimal- adhesion zone of the Baier curve behave as $\mathrm{AF} / \mathrm{FR}$ coatings. The TDF-containing coatings were evaluated with respect to the impact of fluorocarbon content on the settlement of cypris larvae of the barnacle Balanus amphitrite and zoospores of the macrofouling algae Ulva linza and on the release of juvenile barnacles and sporelings of Ulva.

\section{Materials and methods}

\section{Chemical reagents and materials}

Deionized water was prepared to a specific resistivity of at least $18 \mathrm{M} \Omega$ using a Barnstead NANOpure Diamond UV ultrapure water system. Tetraethoxysilane (TEOS), $n$-octadecyl-trimethoxysilane (C18), tridecafluoro-1,1, 2,2-tetrahydrooctyltriethoxysilane (TDF), and n-octyltriethoxysilane $(\mathrm{C} 8)$ were purchased from Gelest, Inc. and were used as received. Ethanol was purchased from Quantum Chemical Corp. Hydrochloric acid and isopropanol were obtained from Fisher Scientific Co. Borosilicate glass microscope slides were obtained from Fisher Scientific, Inc. Silastic ${ }^{\mathbb{R}}$ T2 (Dow Corning) coated slides ca $500 \mu \mathrm{m}$ in thickness, were provided by Dr AB Brennan, University of Florida (Schumacher et al. 2007).

\section{Sol preparation}

The sol/xerogel composition is designated in terms of the molar ratio of Si-containing precursors. Thus, a 50:50 C8/TEOS composition contains 50 mole- $\%$ C 8 and 50 mole- $\%$ TEOS. In all the sol preparations described below, the aqueous $\mathrm{HCl}$ was added last. Unless noted otherwise, all sols were capped and stirred at ambient temperature.

\section{0:50 C8/TEOS}

A mixture of TEOS (2.09 g, $2.24 \mathrm{ml}, 10 \mathrm{mmol}), \mathrm{C} 8$ $(2.78 \mathrm{~g}, 3.16 \mathrm{ml}, 10 \mathrm{mmol})$, isopropanol $(4.0 \mathrm{ml})$, and $0.100 \mathrm{M} \mathrm{HCl}(1.23 \mathrm{ml}, 0.123 \mathrm{mmol})$ was capped and stirred for $24 \mathrm{~h}$. This sample, which did not contain TDF, served as a control xerogel surface.

\section{1:1:48:50 C18/TDF/C8/TEOS}

A mixture of C18 (0.135 g, $0.36 \mathrm{mmol})$, TDF $(0.184 \mathrm{~g}$, $0.36 \mathrm{mmol}), \mathrm{C} 8(4.78 \mathrm{~g}, 17.3 \mathrm{mmol})$, TEOS $(3.75 \mathrm{~g}$, $18.0 \mathrm{mmol})$, ethanol $(8.47 \mathrm{ml})$, and $0.1 \mathrm{M} \mathrm{HCl}(2.27$ $\mathrm{ml}$ ), was stirred for $24 \mathrm{~h}$.

\section{1:4:45:50 C18/TDF/C8/TEOS}

A mixture of $\mathrm{C} 18(0.135 \mathrm{~g}, 0.36 \mathrm{mmol})$, TDF (0.735 g, $1.44 \mathrm{mmol}), \mathrm{C} 8(4.48 \mathrm{~g}, 16.2 \mathrm{mmol})$, TEOS (3.75 g, 
$18.0 \mathrm{mmol})$, ethanol $(11.9 \mathrm{ml})$, and $0.1 \mathrm{M} \mathrm{HCl}(2.27$ $\mathrm{ml}$ ) was stirred for $24 \mathrm{~h}$.

\section{1:9:40:50 C18/TDF/C8/TEOS}

A mixture of $\mathrm{C} 18(0.135 \mathrm{~g}, 0.36 \mathrm{mmol})$, TDF (1.65 g, $3.24 \mathrm{mmol})$, C8 (3.98 g, $14.4 \mathrm{mmol})$, TEOS (3.75 g, $18.0 \mathrm{mmol})$, ethanol $(11.9 \mathrm{ml})$, and $0.1 \mathrm{M} \mathrm{HCl}(2.27$ $\mathrm{ml}$ ) was stirred for $24 \mathrm{~h}$.

\section{1:14:35:50 C18/TDF/C8/TEOS}

A mixture of C18 $(0.135 \mathrm{~g}, 0.36 \mathrm{mmol})$, TDF $(2.57 \mathrm{~g}$, $5.04 \mathrm{mmol}), \mathrm{C} 8(3.48 \mathrm{~g}, 12.6 \mathrm{mmol})$, TEOS $(3.75 \mathrm{~g}$, $18.0 \mathrm{mmol})$, ethanol $(11.5 \mathrm{ml})$ and $0.1 \mathrm{M} \mathrm{HCl}(2.27 \mathrm{ml})$ was stirred for $24 \mathrm{~h}$.

\section{1:19:30:50 C18/TDF/C8/TEOS}

A mixture of C18 (0.135 g, $0.36 \mathrm{mmol})$, TDF (3.49 g, $6.84 \mathrm{mmol})$, C8 (2.99 g, $10.8 \mathrm{mmol})$, TEOS (3.75 g, $18.0 \mathrm{mmol})$, ethanol $(11.5 \mathrm{ml})$, and $0.1 \mathrm{M} \mathrm{HCl}(2.27$ $\mathrm{ml}$ ) was stirred for $24 \mathrm{~h}$.

\section{1:24:25:50 C18/TDF/C8/TEOS}

A mixture of C18 (0.135 g, $0.36 \mathrm{mmol})$, TDF (4.41 g, $8.64 \mathrm{mmol}), \mathrm{C} 8$ (2.49 g, $9.0 \mathrm{mmol})$, TEOS (3.75 g, 18.0 $\mathrm{mmol})$, ethanol $(11.5 \mathrm{ml})$, and $0.1 \mathrm{M} \mathrm{HCl}(2.27 \mathrm{ml})$ was stirred for $24 \mathrm{~h}$.

\section{Xerogel film formation}

Prior to use, glass microscope slides $(25-\mathrm{mm} \times 75$ $\mathrm{mm}$ ) were soaked in piranha solution for $24 \mathrm{~h}$, rinsed with copious quantities of deionized water, soaked in isopropanol for $10 \mathrm{~min}$, air dried and stored at ambient temperature. Xerogel films were formed by spin casting $400 \mu \mathrm{l}$ of the sol precursor onto the microscope slides. A model P6700 spincoater (Specialty Coatings Systems, Inc.) was used at $100 \mathrm{rpm}$ for $10 \mathrm{~s}$ to deliver the sol and at $3000 \mathrm{rpm}$ for $30 \mathrm{~s}$ to coat. Profilometry indicated that the xerogel films cast in this manner were $1-2 \mu$ m thick.

For barnacle cyprid assays, glass $20-\mathrm{mm} \times 60-$ $\mathrm{mm}$ Petri dish bottoms (VWR Scientific, Inc.) were soaked in piranha solution for $24 \mathrm{~h}$, rinsed with copious quantities of deionized water, and stored in an oven at $110^{\circ} \mathrm{C}$ until use. The Petri dish bottoms were cooled to ambient temperature and $600 \mu \mathrm{l}$ of the appropriate sol precursor were added. The Petri dish was manipulated until the bottom surface and $\sim 5 \mathrm{~mm}$ of the side surface were covered. The excess sol precursor was removed via pipette. All coated surfaces (glass slides and Petri dishes) were dried at ambient temperature and humidity for at least 7 days prior to analysis.

\section{Imaging reflectance infrared (IR) microscopy of xerogel samples}

Imaging reflectance IR microscopy was carried out using a Bruker Vertex 70 IR coupled with a Hyperion 3000 IR microscope $\left(4 \mathrm{~cm}^{-1}, 64\right.$ scans, $15 \times$ objective, $64 \times 64$ focal plane array). IR scans were collected in reflectance mode utilizing an FPA (focal plane array) detector with a detection area of 200 $\mu \mathrm{m} \times 200 \mu \mathrm{m}$. Samples of the 1:4:45:50 and 1:14:35:50 C18/TDF/C8/TEOS xerogel on aluminum-coated glass slides were prepared by spin casting $400 \mu \mathrm{l}$ of the sol precursor onto $25-\mathrm{mm} \times 75-\mathrm{mm} \times 1.1-\mathrm{mm}$ borosilicate float glass microscope slides coated with $50 \pm 1 \mathrm{~nm}$ aluminum (Deposition Research Laboratories, Inc.) and air drying the films at ambient temperature for at least 7 days. One set of xerogel films was analyzed following air-drying while a second set of xerogel films was soaked in deionized water at $25^{\circ} \mathrm{C}$ for $24 \mathrm{~h}$ and then dried at ambient temperature and humidity for $2 \mathrm{~h}$. The IR data collected for the $200 \times 200 \mu \mathrm{m}$ area was baseline corrected relative to the aluminum-coated slide as a blank and then integrated over the C-H stretching region (2800$3000 \mathrm{~cm}^{-1}$ ) and the C-F stretching region (1223$1275 \mathrm{~cm}^{-1}$ ). The 2D color images of relative intensity were then converted to 32 bit black and white images using Image-J software, where the "color" intensity was converted to gray-scale intensity. The ratio of the two images $(\mathrm{C}-\mathrm{F} / \mathrm{C}-\mathrm{H})$ was then calculated using the Ratio Plus plugin, resulting in a single image in which black areas pertain to an enhancement of fluorocarbon signal or reduced signal pertaining to hydrocarbon species and white areas pertain to enhanced signal from hydrocarbon species or reduced signal from fluorocarbon species.

\section{Atomic force microscope (AFM) imaging measurements}

The samples were imaged by AFM using a Nanoscope $^{\circledR}$ Dimension 3100 scanning probe microscope (Bruker AXS, Santa Barbara, CA) in an environmentally controlled laboratory with the relative humidity set at $25 \%$. Photomicrographs were acquired using TappingMode ${ }^{\mathrm{TM}}$ AFM (TM-AFM) under ambient conditions. With a TM-AFM, the tip is driven at a known amplitude and frequency of oscillation which is typically near the cantilever resonance. The oscillatory motion is reduced as the tip is brought closer to the surface. The changes in the amplitude allow the AFM to track the surface, providing topographical 
information. A single crystal silicon Nanoprobe ${ }^{\mathrm{TM}}$ with a spring constant of $c a 17-43 \mathrm{~N} / \mathrm{m}$ and resonance frequencies in the $262-359 \mathrm{kHz}$ range was used to examine the xerogel film surfaces. TappingMode ${ }^{\mathrm{TM}}$ AFM images were acquired at a $1-\mu \mathrm{m}$ and $5-\mu \mathrm{m}$ scan size with the z-scale set to $100-\mathrm{nm}$.

Phase mode AFM imaging can distinguish surface features that are related to surface composition differences. Phase shifts are registered as bright and dark regions in the phase AFM image. For the phase mode images of this study, brighter regions indicate stiffer material whereas darker regions indicate a softer material.

\section{Comprehensive contact angle analysis}

The xerogel films were stored in air prior to characterization. Comprehensive contact angle analyses were performed in air (Zisman 1964; Baier and Meyer 1992). The approximate sampling depth of the contact angle technique is $5 \AA$. Up to 13 different diagnostic liquids were utilized for the analysis of each sample, viz. water, glycerol, formamide, thiodiglycol, methylene iodide, 1-bromonaphthalene, 1-methylnaphthalene, dicyclohexyl, $n$-hexadecane, $n$-tridecane, $n$-decane, $n$-octane, and $n$-heptane. The liquid/vapor surface tensions of these liquids were determined directly; reference values for the liquid/vapor surface tensions are not used. The technique of "advanced angle" analysis was used, wherein a sessile drop of liquid (8-15 $\mu$ l depending on the viscosity of the liquid) is placed on the sample surface and the angle of contact $(\theta)$ between the liquid and the solid is measured with a contact angle goniometer [RameHart, Model NRL 100]; both sides of the droplet profile are measured. Another droplet of the same fluid is placed on top of the first droplet (the fluid is advanced across the surface), and the measurements are repeated. If the contact angles for the first droplet are $\leq 20^{\circ}$, no further measurements are taken for that liquid on the sample; fluids having contact angles of $\leq 20^{\circ}$ use a relatively large amount of the limited sample surface area. Zisman plots were constructed by plotting the cosine of the average angle measured for each liquid against the liquid/vapor surface tension of the diagnostic liquid. A linear least squares analysis is performed to determine the sample's critical surface tension $\left(\gamma_{C}\right)$ at the $\cos \theta=4$ axis. In cases of large data scatter (non linearity), the data for the spreading liquid $(\theta=\theta)$ with the greatest liquid/vapor surface tension and for those liquids closest to, but greater than, in surface tension to the first spreading liquid are used to determine $\gamma_{C}$. The data were also treated as described by Owens and Wendt (1969), Kaelbe (1970), and Nyilas et al. (1977) to give the surface free energy $\left(\gamma_{\mathrm{S}}\right)$, as well as its polar $\left(\gamma_{\mathrm{P}}\right)$ and dispersion $\left(\gamma_{\mathrm{D}}\right)$ components (Baier and Meyer 1992), after the xerogel films were aged in air or soaked in deionized water for $48 \mathrm{~h}$ and then air-dried for $1 \mathrm{~h}$.

Static water contact angles $\left(\theta_{\mathrm{Ws}}\right)$ were measured by the sessile drop technique where the angle between a $15-\mu 1$ drop of water and the xerogel surface was measured with a contact angle goniometer [RameHart, Model NRL 100]; both sides of the droplet profile were measured.

\section{Biofouling assays with barnacles}

Barnacle cypris larvae were obtained from Duke University Marine Lab. Glass standards were acid washed in $10 \% \mathrm{HCl}$ for $2 \mathrm{~h}$, rinsed well with deionized water, and dried completely prior to cyprid settlement. Silastic ${ }^{\circledR}$ T2 (T2) coated slides (Feinberg et al. 2003) were included in the assays to provide a standard FR coating.

\section{Cyprid settlement assays}

Approximately $10 \mathrm{ml}$ of seawater were added to each xerogel-coated Petri dish. This volume covered the bottom of the dish and allowed the cyprids free range of movement across the surface. A 400- $\mu$ l drop of seawater containing between 30 and 60 2-4-day-old barnacle cypris larvae was then added to each of the dishes. After $48 \mathrm{~h}$ the percentage of cyprids that had settled in each dish was counted. The average percentage settlement for each of the experimental coatings was compared to the controls. Glass and T2 coated dishes were used as standard settlement substrata.

\section{Barnacle removal assays}

A 400- $\mu$ 1 drop of seawater containing between 20 and 40 2-4-day-old cypris larvae was placed on the surface of the xerogel film-coated glass microscope slides. The surfaces with larvae were placed in a constant temperature incubator at $25^{\circ} \mathrm{C}$ on a $12 \mathrm{~h}: 12 \mathrm{~h}$ light:dark cycle and the larvae were allowed to settle for $48 \mathrm{~h}$. Newly metamorphosed juveniles on their respective coatings were transferred to growth chambers where they were fed the unicellular green alga Dunaliella tertiolecta and the diatom Skeletonema costatum for 2 weeks, and then a mixture of $D$. tertiolecta, S. costatum, and naupliar larvae of Artemia sp. for an additional week. Juveniles were then transferred to a 16-1 aquarium tank in an automated rack system with temperature, salinity, and $\mathrm{pH}$ monitors and programmed for a $10 \%$ daily water change. Barnacles in the tank were fed a 500-ml flask 
of Artemia sp. three times a week for 4-6 weeks, which is the time it took the juvenile barnacles to reach a basal plate diameter of $3-5 \mathrm{~mm}$, the minimum size necessary to conduct force gauge tests according to ASTM D 5618.

The procedures for critical removal stress were followed from ASTM D 5618 with the following modifications: (i) the force measuring device was operated by a motorized stand, ensuring a constant application of force during dislodgement, and (ii) barnacle dislodgement studies from coatings were performed under water. The apparatus consists of an IMADA ZP-11 digital force gauge mounted on an IMADA SV-5 motorized stand. The slides are clamped into a custom-built Plexiglas chamber that allowed their complete submersion during dislodgement tests.

Juvenile barnacles were selected for testing based on healthy appearance and minimum size requirements. Only barnacles positioned at least $5 \mathrm{~mm}$ from the edges of the slide were tested. Other barnacles in close proximity to the test subject were removed if they could potentially interfere with measurements. Prior to removal of barnacles each basal plate was photographed using a Canon ${ }^{\mathrm{TM}}$ EOS 10D camera attached to an Olympus ${ }^{\mathrm{TM}}$ SZX12 dissecting microscope and images were later used to calculate basal plate areas using NIH's ImageJ software. After photographs were taken, the slide was clamped into the Plexiglas chamber. The force gauge mounted on the motorized stand was used to apply a shear force to the base of the barnacles at a rate of $\sim 4.5 \mathrm{~N} \mathrm{~s}^{-1}$ until the organism was detached. Force was applied parallel to the film surface. The force required for detachment was noted and observations were made as to the mode of failure. If any portion of the base of the organism was left attached to the substratum, the test was deemed void for removal. The surfaces were examined visually for damage to the xerogel film caused by barnacle removal and by stereomicroscope if there were any ambiguity. The critical removal stress was calculated by dividing the force $(\mathrm{F}$, Newtons) required to remove the test subject by the area of attachment $\left(\mathrm{A}, \mathrm{mm}^{2}\right)$. For barnacles where a portion of the base of the organism was left attached to the substratum, the remaining basal plate was photographed and the area was calculated as described above and used to calculate the exact fraction remaining after testing (fraction BPR).

\section{Biofouling assays with Ulva}

Coatings applied to glass slides were equilibrated in circulating deionized water for $48 \mathrm{~h}$ prior to the start of assays with algae. One hour prior to the assay, the slides were transferred to artificial seawater (ASW).
Silastic ${ }^{\circledR}$ T2-coated slides were included in the assays to provide a standard FR coating.

\section{Settlement of zoospores of Ulva}

Fronds of Ulva linza were collected from Llantwit Major, Wales $\left(51840^{\prime} \mathrm{N} ; 3848^{\prime} \mathrm{W}\right)$ and a spore suspension of $1.0 \times 10^{6}$ spores $\mathrm{ml}^{-1}$ was prepared by the method of Callow et al. (1997). Three replicate slides of each treatment were placed in individual wells of "quadriperm" polystyrene culture dishes (Greiner) and $10 \mathrm{ml}$ of spore suspension were added. Dishes were incubated in the dark for $1 \mathrm{~h}$ at $\sim 20^{\circ} \mathrm{C}$. After incubation, the slides were gently washed in ASW to remove unattached (swimming) spores. Slides were fixed in $2.5 \%$ glutaraldehyde. The density of spores attached to the surfaces was counted using an image analysis system attached to a fluorescence microscope. Spores were visualized by autofluorescence of chlorophyll. Counts were made for thirty fields of view (each $0.17 \mathrm{~mm}^{2}$ ), $1 \mathrm{~mm}$ apart over the central region of each slide, using image analysis software (Axiovision 4.8.1, Carl Zeiss imaging systems) attached to a Zeiss epifluorescence microscope (Callow et al. 2002). Spore settlement data are expressed as the mean number of spores adhered per $\mathrm{mm}^{2}$ with $95 \%$ confidence limits $(n=+90)$.

\section{Adhesion strength of sporelings of Ulva}

Spores were allowed to settle as described above. After washing away unattached spores, spores that had attached to the test surfaces were cultured in dishes containing supplemented seawater medium that was changed every 2 days (Starr and Zeikus 1987). The dishes were placed in an illuminated incubator $(75 \mathrm{~mW}$ $\mathrm{m}^{-2} \mathrm{~s}^{-1}$ incident irradiation) for 7 days during which time the spores germinated and developed into sporelings.

The biomass produced was quantified by measuring the fluorescence of chlorophyll in a Tecan fluorescence plate reader (excitation $=\$ 430 \mathrm{~nm}$, emission $=\$ 670 \mathrm{~nm}$ ) (Finlay et al. 2008a). Fluorescence was measured as relative fluorescence units (RFU) and was directly proportional to the quantity of biomass present. The RFU value for each slide was the mean of 70 point fluorescence readings taken from the central region (middle third of the slide over a 1 in $\times 1$ in region).

The strength of adhesion of the sporelings was determined by exposing the slides to a range of impact pressures from an automated water jet, which traversed the central region (middle third of the slide over a 1 in $\times 1$ in region) of each slide (Finlay et al. 2002). One replicate slide of each coating was exposed to one 
of five impact pressures. Pressures were selected to provide the widest range of biomass removal possible. The biomass that remained in the sprayed area after exposure to the water jet was quantified as described above. The percentage removal of sporelings was determined by comparison of the biomass (RFU) before exposure with that remaining attached to the coatings after exposure to the water jet. The critical impact pressure to remove $50 \%$ of the biomass $\left(\mathrm{CP}_{50}\right)$ was determined from plots of percentage removal vs water impact pressure (Finlay et al. 2008a).

\section{Results}

\section{Xerogel surfaces}

A series of xerogel surfaces containing C18, TDF, C8 and TEOS were prepared from sols with the following mole- $\%$ ratios: 1:1:48:50, 1:4:45:50, 1:9:40:50, 1:14:35:50, 1:19:30:50 and 1:24:25:50 C18/TDF/C8/ TEOS, respectively. A 1:49:50 C18/TDF/TEOS xerogel surface (C18/TDF/TEOS xerogel in the remainder of the manuscript) was also prepared and a 50:50 C8/ TEOS xerogel surface (C8/TEOS xerogel in the remainder of the manuscript) was prepared as a xerogel control. The xerogel films prepared by spin coating were 1-2 $\mu \mathrm{m}$ thick as measured by profilometry. All of the xerogel films of this study were optically transparent.

The xerogel surfaces were aged in air at ambient temperature for 7 days and were then examined by comprehensive advanced contact angle analyses to give values of the critical surface tension $\left(\gamma_{\mathrm{C}}\right)$ (Zisman 1964; Baier and Meyer 1992) and the surface free energy $\left(\gamma_{\mathrm{S}}\right)$ (Owens and Wendt 1969, Table 1). The static water contact angles, $\theta_{\mathrm{Ws}}$, were measured for all xerogel surfaces described in this study and are compiled in
Table 1. For the TDF-containing xerogels, values of $\gamma_{\mathrm{C}}$ varied between 11.5 and $19.8 \mathrm{mN} \mathrm{m}^{-1}$, values of $\gamma_{\mathrm{S}}$ varied between 16.1 and $21.8 \mathrm{mN} \mathrm{m}^{-1}$ and values of $\theta_{\mathrm{Ws}}$ varied between $97.0^{\circ}$ and $110.3^{\circ}$.

To evaluate the impact of water on surface properties, values of $\theta_{\mathrm{Ws}}$ and $\gamma_{\mathrm{s}}$ were measured before and after the xerogel surfaces were immersed in deionized water for $48 \mathrm{~h}$ and air-dried for $1 \mathrm{~h}$. The values of $\theta_{\mathrm{Ws}}$ and $\gamma_{\mathrm{S}}$, pre- and post-immersion in deionized water, are compared graphically in Figure 1. In pair-wise comparisons (Student $t$-test), values of $\gamma_{\mathrm{S}}$ pre-and post-immersion in water are essentially unchanged with no significant differences $(p>0.09)$ with the exception of the 1:19:30:50 C18/TDF/C8/TEOS xerogel where the increase in $\gamma_{\mathrm{S}}$ upon immersion in water was significant $(p<0.01)$.

The 1:4:45:50 and 1:14:35:50 C18/TDF/C8/TEOS xerogels were examined by AFM prior to immersion in water and after $24 \mathrm{~h}$ immersion in deionized water. Immersed surfaces were air-dried for $1 \mathrm{~h}$ prior to imaging in air. Figure 2 shows representative images of the 1:4:45:50 $\mathrm{C} 18 / \mathrm{TDF} / \mathrm{C} 8 / \mathrm{TEOS}$ xerogel prior to immersion (panels a-c) and post-immersion in deionized water (panels $\mathrm{d}-\mathrm{f}$ ). The phase images of the preimmersion samples (panels b and c) clearly show inhomogeneities across the surface, which may be linked to phase segregation. After immersion in water, the features of inhomogeneity are smaller and are more evenly distributed across the surface.

Values of the root-mean-square roughness $\left(R_{\mathrm{rms}}\right)$ for the 1:4:45:50 and 1:14:35:50 C18/TDF/C8/TEOS xerogel surfaces pre- $(1.87 \pm 0.20$ and $2.31 \pm$ $0.21 \mathrm{~nm}$, respectively, where error limits are \pm one standard deviation [SD]) and post-immersion $(0.93 \pm 0.05$ and $0.95 \pm 0.03 \mathrm{~nm}$, respectively $)$ in deionized water were calculated on six $5-\mu \mathrm{m} \times 5-\mu \mathrm{m}$ images for each sample, where $R_{\mathrm{rms}}$ is defined as the

Table 1. Static water contact angles $\left(\theta_{\mathrm{Ws}}\right)$, critical surface tensions $\left(\gamma_{\mathrm{C}}\right)$ and surface energies $\left(\gamma_{\mathrm{S}}\right)$ for the xerogel surfaces of this study and glass, T2 and C8/TEOS standards.

\begin{tabular}{|c|c|c|c|}
\hline Sample & $\theta_{\mathrm{Ws}}{ }^{a}$, & $\gamma_{\mathrm{C}}^{b}, \mathrm{mN} \mathrm{m}^{-1}$ & $\gamma_{\mathrm{s}}^{c}, \mathrm{mN} \mathrm{m}^{-1}$ \\
\hline Glass & $21 \pm 1$ & - & - \\
\hline $\mathrm{T} 2$ & $109^{d}-$ & $23.0 \pm 0.4^{e}$ & $23.0 \pm 0.4^{d}$ \\
\hline 50:50 C8/TEOS & $100^{f}$ & $21.3 \pm 0.1^{f}$ & $27.1 \pm 0.3^{f}$ \\
\hline 1:1:48:50 C18/TDF/C8/TEOS & $110.3 \pm 0.7$ & - & $21.8 \pm 1.6$ \\
\hline 1:4:45:50 C18/TDF/C8/TEOS & $102.4 \pm 0.8$ & $19.3 \pm 1.4$ & $21.8 \pm 2.8$ \\
\hline 1:9:40:50 C18/TDF/C8/TEOS & $100.8 \pm 1.6$ & $19.8 \pm 0.5$ & $20.1 \pm 1.4$ \\
\hline 1:14:35:50 C18/TDF/C8/TEOS & $98.9 \pm 1.6$ & $18.8 \pm 0.2$ & $17.6 \pm 0.5$ \\
\hline 1:19:30:50 C18/TDF/C8/TEOS & $100.7 \pm 0.3$ & $11.5 \pm 2.3$ & $17.2 \pm 0.5$ \\
\hline 1:24:25:50 C18/TDF/C8/TEOS & $100.8 \pm 0.1$ & $12.4 \pm 0.5$ & $16.1 \pm 3.0$ \\
\hline 1:49:50 C18/TDF/TEOS & $97.0 \pm 1.1$ & - & $17.3 \pm 0.5$ \\
\hline
\end{tabular}

${ }^{a}$ Mean of five independent measurements for coatings stored in air prior to measurement. \pm one SD. ${ }^{b}$ Mean of two independent measurements for coatings stored in air for 7 days prior to measurement. ${ }^{c}$ Mean of three independent measurements for coatings stored in air for 7 days prior to measurement. ${ }^{d}$ From Tang et al. (2005). ${ }^{e}$ From Feinberg et al. (2003). From Gunari et al. (2011). 

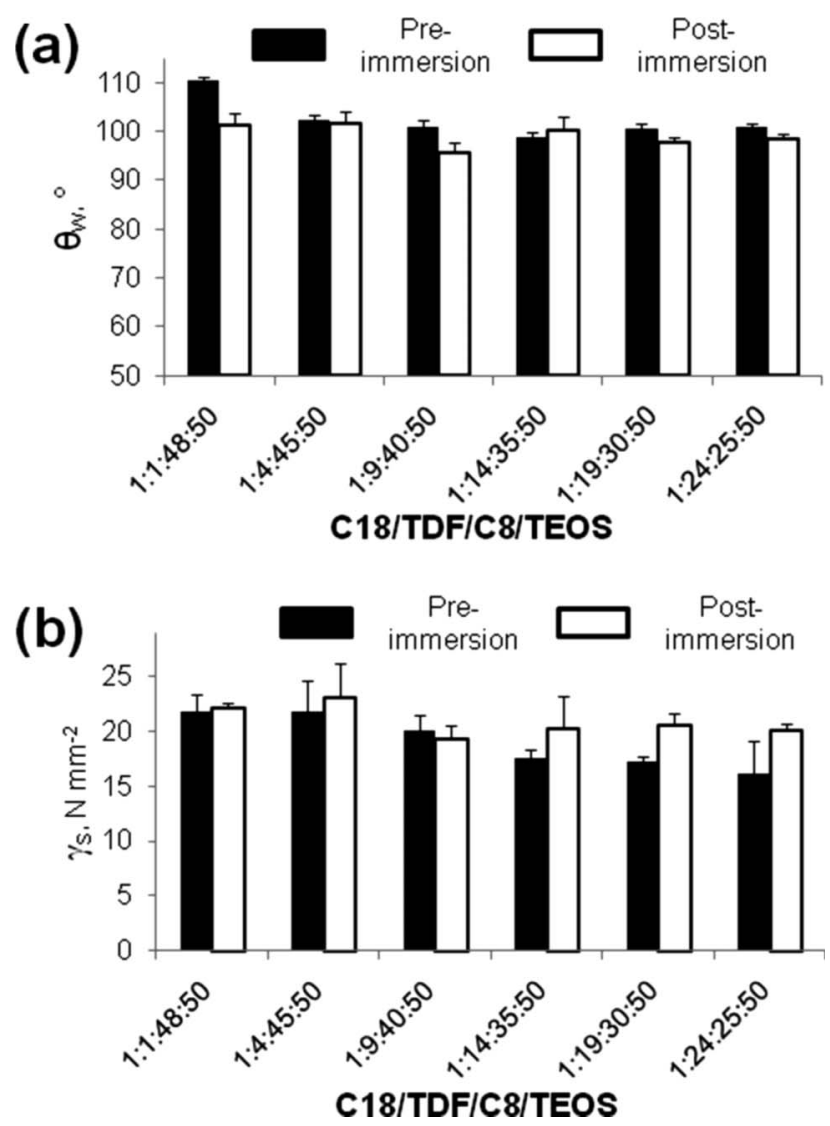

Figure 1. Changes in (a) static water contact angle $\left(\theta_{\mathrm{Ws}}\right)$ and (b) surface energy $\left(\gamma_{\mathrm{S}}\right)$ between xerogel samples air-dried for 7 days (black bars) and xerogels samples soaked for $48 \mathrm{~h}$ in deionized water (white bars). Error bars represent \pm one $\mathrm{SD}$ from the mean for three independent measurements preand post-immersion.

root mean square average of the topographic deviations $(t)$ as shown in Equation (1):

$$
R_{\mathrm{rms}}=\sqrt[4]{\left.\left(t \sum_{i=1}^{N} f_{i}-\bar{t}\right)^{2}\right)}
$$

Values of $R_{\text {rms }}$ pre- and post-immersion in deionized water as well as changes in the peak-to-valley heights are shown graphically in Figure 3. Immersion in water for both surfaces led to statistically significant decreased surface roughness in pair-wise comparisons (Student $t$-test, $p<0.0001$ for both surfaces) and decreased peak-to-valley heights $(p=+0.0002$ and $p<0.0001$ for the $1: 4: 45: 50$ and $1: 14: 35: 50 \mathrm{C} 18 /$ $\mathrm{TDF} / \mathrm{C} 8 / \mathrm{TEOS}$ xerogel surfaces, respectively).

Samples of the 1:4:45:50 and 1:14:35:50 C18/TDF/ C8/TEOS xerogel on aluminum-coated glass slides were also examined by imaging reflectance IR microscopy. The sol-gel process produces xerogels with residual silanol functionality $\left(3200-3700 \mathrm{~cm}^{-1}\right)$, which is uniformly distributed across the 1:4:45:50 and
1:14:35:50 C18/TDF/C8/TEOS xerogels (IR microscopy images not shown) as well as across the C8/ TEOS and 1:49:50 C18/C8/TEOS xerogel surfaces of earlier studies (Gunari et al. 2011). In contrast, IR microscopy images of the integrated C-F stretching region $\left(1223-1275 \mathrm{~cm}^{-1}\right)$ and the integrated $\mathrm{C}-\mathrm{H}$ stretching region $\left(2800-3000 \mathrm{~cm}^{-1}\right)$ show some segregation into higher $\mathrm{C}-\mathrm{F} /$ lower $\mathrm{C}-\mathrm{H}$-containing features and lower $\mathrm{C}-\mathrm{F} /$ higher $\mathrm{C}-\mathrm{H}$-containing features across the $1: 4: 45: 50$ and $1: 14: 35: 50 \quad \mathrm{C} 18 / \mathrm{TDF} / \mathrm{C} 8 / \mathrm{TEOS}$ xerogel surfaces. These features are illustrated in Figure 4 for the 1:14:35:50 C18/TDF/C8/TEOS xerogel prior to immersion (panels $\mathrm{a}$ and $\mathrm{b}$ ) and post-immersion in deionized water for $24 \mathrm{~h}$ (panels $\mathrm{d}$ and e). A ratio of the two images $(\mathrm{C}-\mathrm{F} / \mathrm{C}-\mathrm{H})$, resulting in a single image in which black areas reflect regions with enhanced signal from fluorocarbon species or decreased signal from hydrocarbon species and white areas reflect regions with enhanced signal from hydrocarbon species or decreased signal from fluorocarbon species as shown in panel $\mathrm{c}$ and $\mathrm{f}$ of Figure 4. Enhanced fluorocarbon and hydrocarbon features on the $\sim 1 \mu \mathrm{m}$-scale are discernable pre- and post-immersion in water. It should be noted that these features are with respect to the "bulk" surface, ie the entire thickness, and are not necessarily an indication of chemical identity at the surface.

\section{Settlement of cypris larvae and removal of juvenile barnacles of $B$. amphitrite}

The settlement of 2-4-day-old barnacle cypris larvae that were placed on the xerogel coatings and the glass and T2 standard surfaces was compared (Figure 5). There was no significant difference in settlement between individual xerogel test coatings or between xerogel test coatings and glass or T2 standards (ANOVA, $p=\theta .233$ ). The fraction of settled cyprids among the xerogel coatings was between 0.32 and 0.59 .

The strength of attachment of juvenile barnacles to the seven TDF-containing xerogel surfaces, the C8/ TEOS xerogel and glass and T2 standards was measured via force-gauge measurements with forces applied in shear. All barnacles on both the C8/TEOS xerogel and the glass standard broke when force was applied to them in shear, and left a complete or partial basal plate attached to the surface. For the glass standard, the fraction of the barnacle basal plate remaining was 1.00 , ie essentially all of the barnacle basal plate remained on the glass surface. For the $\mathrm{C} 8$ / TEOS xerogel, the fraction of the barnacle basal plate remaining was $0.80 \pm 0.04$. All of the TDF-containing xerogel surfaces as well as the T2 standard performed as FR surfaces as shown in Figure 6a. The 1:1:48:50 $\mathrm{C} 18 / \mathrm{TDF} / \mathrm{C} 8 / \mathrm{TEOS}$ xerogel gave complete release of 

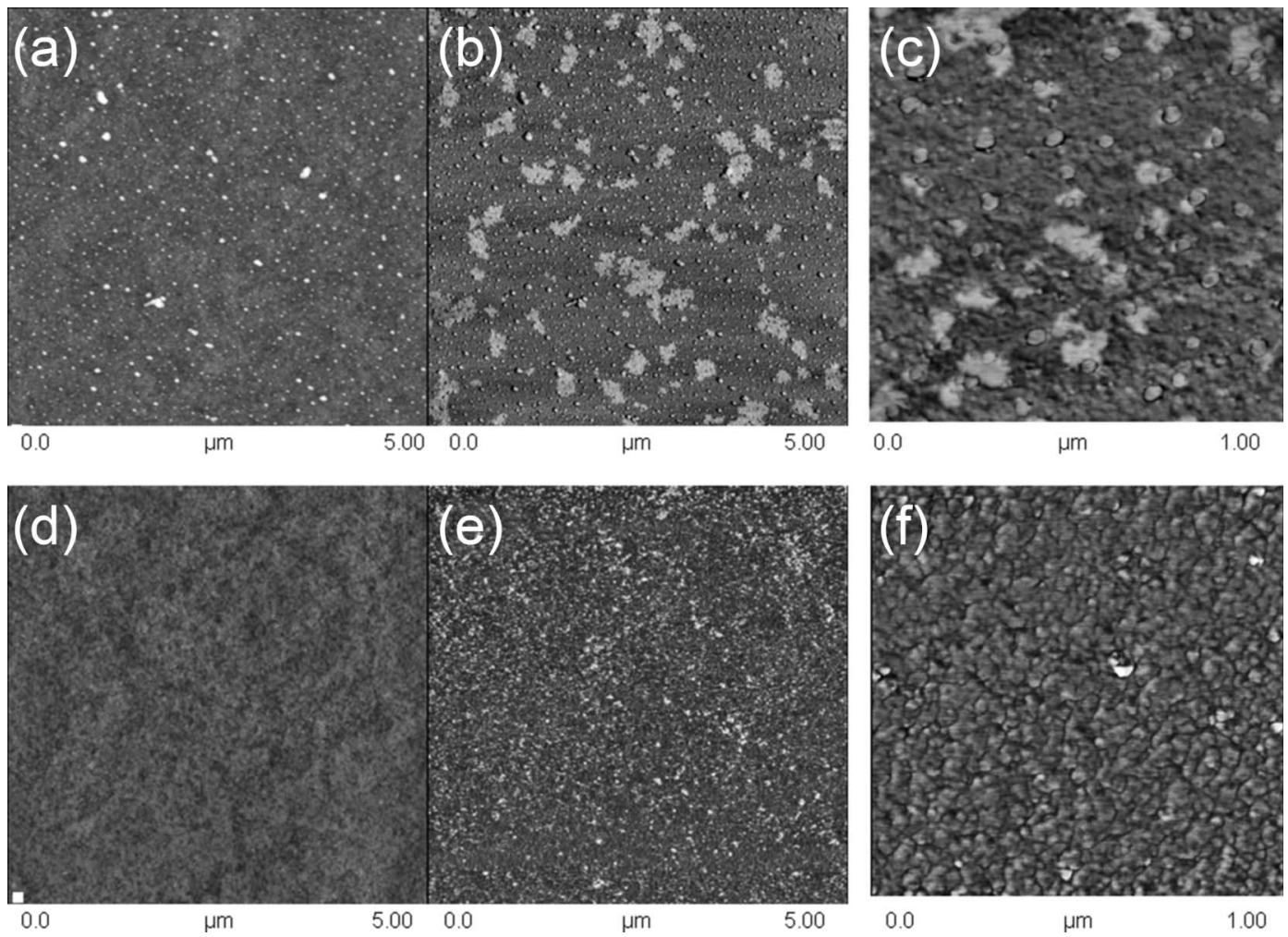

Figure 2. AFM images of the 1:4:45:50 C18/TDF/C8/TEOS xerogel. Panels (a)-(c) are the surfaces prior to immersion in deionized water. Panels (d)-(f) are post-immersion for $24 \mathrm{~h}$ in deionized water and air-dried for $1 \mathrm{~h}$. Panels (a) and (d) compare AFM height images (image size: $5 \mu \mathrm{m} \times 5 \mu \mathrm{m}$, Z-range: $100 \mathrm{~nm}$ ). Panels (b) and (e) compare the subsequent phase images. Panels (c) and (f) compare the phase images acquired at a $1 \mu \mathrm{m} \times 1 \mu \mathrm{m}$ scan size. All AFM images were acquired in air.

$30 \%$ of the attached barnacles $(6 / 20$ barnacles removed completely) while the $\mathrm{C} 18 / \mathrm{TDF} / \mathrm{TEOS}$ xerogel gave complete release of $20 \%$ of attached barnacles $(4 / 20$ barnacles removed completely). The 1:4:45:50 and the 1:14:35:50 C18/TDF/C8/TEOS xerogels (fraction removed completely $=4.00$ and 0.94 , respectively) were comparable to the $\mathrm{T} 2$ standard (fraction removed completely $=40.93$, Figure 2a). The 1:9:40:50, $1: 19: 30: 50$ and 1:24:25:50 C18/TDF/C8/ TEOS xerogels gave intermediate performance (fraction removed completely $=0.69-0.85)$.

There was a significant difference in critical removal stress (CRS) between test coatings (ANOVA $p<0.001)$. The value of CRS for the 1:1:48:50 C18/ $\mathrm{TDF} / \mathrm{C} 8 / \mathrm{TEOS}$ xerogel surface $(0.24 \pm 0.01 \mathrm{MPa}$, Figure 6b) was significantly higher in comparison to the other TDF-containing xerogel surfaces and the T2 standard (in pair-wise comparisons using the Student $t$-test). Values of CRS for the 1:4:45:50, 1:9:40:50, 1:14:35:50, $1: 19: 30: 50$ and 1:24:25:50 C18/TDF/C8/ TEOS xerogel surfaces and the C18/TDF/TEOS xerogel surface were 0.12 to $0.20 \mathrm{MPa}$. These values are not significantly different from the CRS for the T2 surface $(0.14 \pm 0.01 \mathrm{MPa})$. The value of CRS for the 1:14:35:50 C18/TDF/C8/TEOS xerogel surface
$(0.12 \pm 0.01 \mathrm{MPa})$ was significantly lower in comparison to CRS for the C18/TDF/TEOS xerogel surface $(0.20 \pm 0.02 \mathrm{MPa})$.

Berglin et al. (2001) suggested that the remaining fraction of the basal plate left on a surface appeared to be a function of barnacle bioadhesive bond strength and that it could be used as a measure of the efficacy of FR coatings. For barnacles not completely removed, the percentage of the basal plate remaining (BPR) was calculated with digital image analysis. These results were combined with data for barnacles completely removed (fraction $\mathrm{BPR}=4.0$ ) and are shown in Figure $6 \mathrm{c}$. The fraction of the BPR on the T2 standard was $0.02 \pm 0.01$ (Figure 6c). In pair-wise comparisons, the $1: 4: 45: 50$ and $1: 14: 35: 50 \mathrm{C} 18 / \mathrm{TDF} / \mathrm{C} 8 /$ TEOS xerogel surfaces retained significantly less of the basal plate $(p<0.05)$ than the T2 standard, the 1:1:48:50 C18/TDF/C8/TEOS xerogel and the C18/ TDF/TEOS xerogel retained significantly more of the basal plate than the T2 standard and the other TDFcontaining xerogels $(p<0.02)$, while the glass standard and C8/TEOS xerogel control retained essentially all of the basal plate (fraction BPR $=4.00$ and $0.80 \pm 0.04$, respectively), which was significantly greater than all of the other surfaces $(p<0.0001)$. 


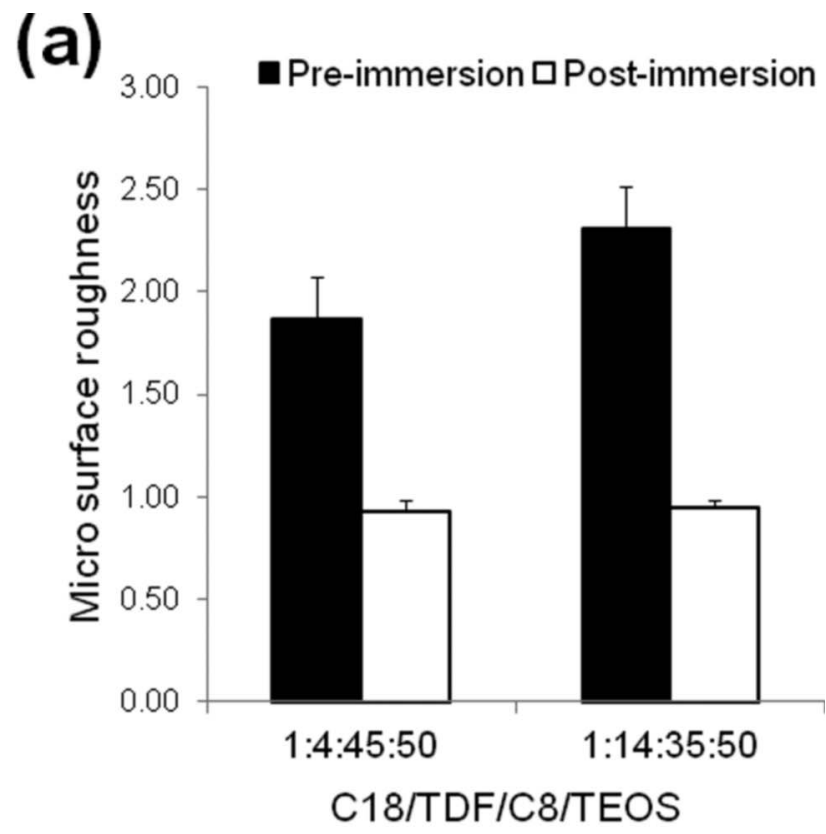

(b)

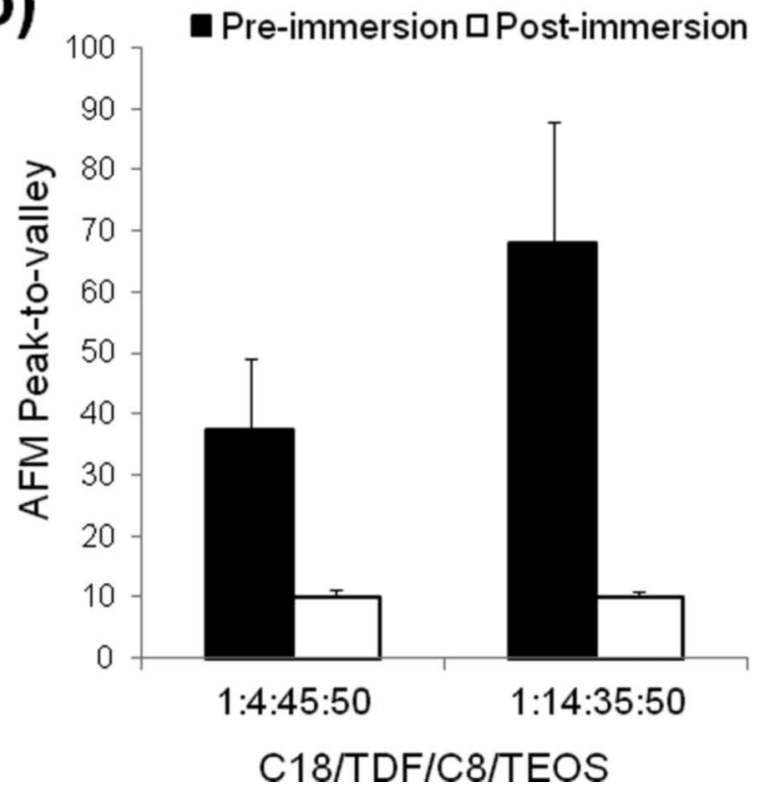

Figure 3. Changes in surface topography for the 1:4:45:50 and 1:14:35:50 C18/TDF/C8/TEOS xerogels as measured by changes in (a) micro surface roughness and (b) AFM peakto-valley distances pre-immersion (black bars) and postimmersion (white bars) for $24 \mathrm{~h}$ in deionized water and airdried for $1 \mathrm{~h}$. Averages were calculated from measurements on six $5 \mu \mathrm{m} \times 5 \mu \mathrm{m}$ images. Error bars represent one SD from the mean.

\section{Settlement and removal of zoospores of Ulva}

Settlement of zoospores, the growth of sporeling biomass and the impact pressure needed to remove $50 \%$ from the TDF-containing xerogel surfaces, the
C8/TEOS xerogel control, and the T2 standards were examined. Spore settlement densities on the C18/TDF/ C8/TEOS coatings and the C8/TEOS xerogel did not follow a trend in terms of composition of the $\mathrm{C} 18$ / $\mathrm{TDF} / \mathrm{C} 8 / \mathrm{TEOS}$ xerogels (Figure 7). One-way analysis of variance and Tukey tests indicated significant differences among the C8/TEOS control and TDFcontaining coatings $\left(F_{7,712}=\$ 33.0 p<0.05\right)$. Settlement densities on the 1:1:48:50 and 1:24:25:50 C18/ $\mathrm{TDF} / \mathrm{C} 8 / \mathrm{TEOS}$ xerogels were significantly lower in comparison to settlement on the C8/TEOS xerogel control or the other TDF-containing xerogels. Zoospore settlement densities on the 1:4:45:50 C18/TDF/ C8/TEOS xerogel and the C18/TDF/TEOS xerogel were not significantly different in comparison to those on the C8/TEOS xerogel control. Settlement densities were highest on the 1:4:45:50, 1:9:40:50, 1:14:35:50, and 1:19:30:50 C18/TDF/C8/TEOS xerogels, which are the mid-range of the $\mathrm{TDF} / \mathrm{C} 8$ ratios, and were not significantly different from one another.

\section{Strength of attachment of sporelings of Ulva}

Sporelings grew well and after 7 days, a green covering was visible on all surfaces. The TDF-containing xerogels and the C8/TEOS control and glass and T2 standards were exposed to a range of water pressures $(20-54 \mathrm{kPa})$ to determine the critical water pressure $\left(\mathrm{CP}_{50}\right)$ required to remove $50 \%$ of 7 -day sporeling biomass (Finlay et al. 2008a). These values are shown graphically in Figure 8. Values of $\mathrm{CP}_{50}$ for all of the $\mathrm{C} 18 / \mathrm{TDF} / \mathrm{TDF} / \mathrm{TEOS}$ xerogels and the C8/TEOS xerogel fell in the range $23.5-36 \mathrm{kPa}$ and are comparable to $\mathrm{CP}_{50}(23 \mathrm{kPa})$ for the $\mathrm{T} 2$ surface. The similarity of $\mathrm{CP}_{50}$ for the TDF-containing xerogels and $\mathrm{Cp}_{50}$ for the T2 surfaces was confirmed in a second experiment (see Supporting Information [Supplementary material is available via a multimedia link on the online article webpage]).

A value of $\mathrm{CP}_{50}$ could not be determined for the glass standard. At the highest pressure examined (54 $\mathrm{kPa}$ ), the fraction of sporelings removed was $<0.2$. In previous studies, $\mathrm{CP}_{50}$ for glass has been estimated at $>200 \mathrm{kPa}$ (Finlay et al. 2008b) and, in the current study, would be estimated to be at least $100 \mathrm{kPa}$.

\section{Discussion}

Earlier studies of xerogel surfaces constructed from sol gels with short-chain ( 8 carbon atoms) organic functionality indicated that these materials had homogeneous surfaces both topographically and chemically (Tang et al. 2005; Bennett et al. 2010; Finlay et al. 2010). SEM studies of several xerogel surfaces indicate that these surfaces are uniform, uncracked, and 

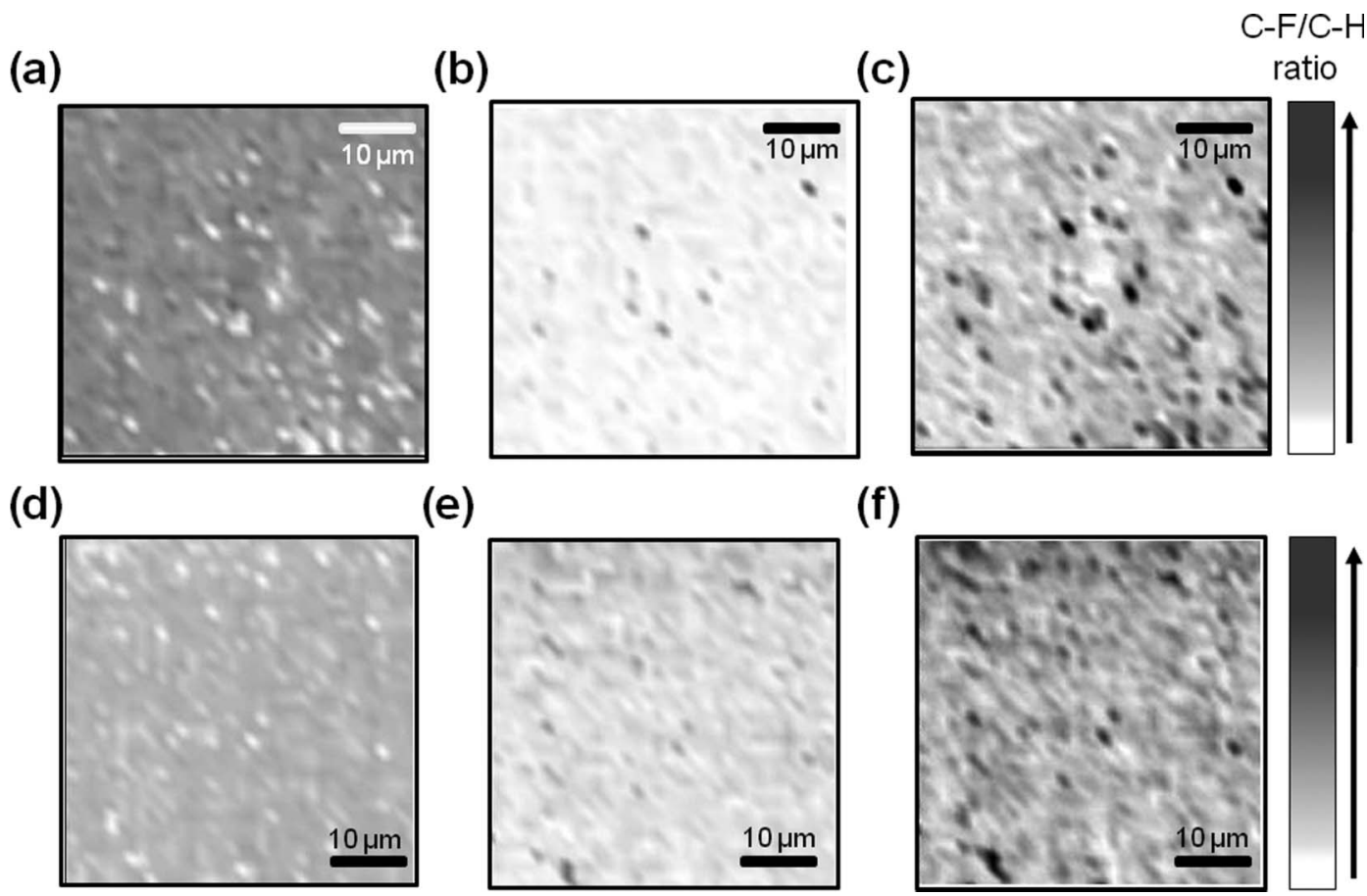

(e)

(f)
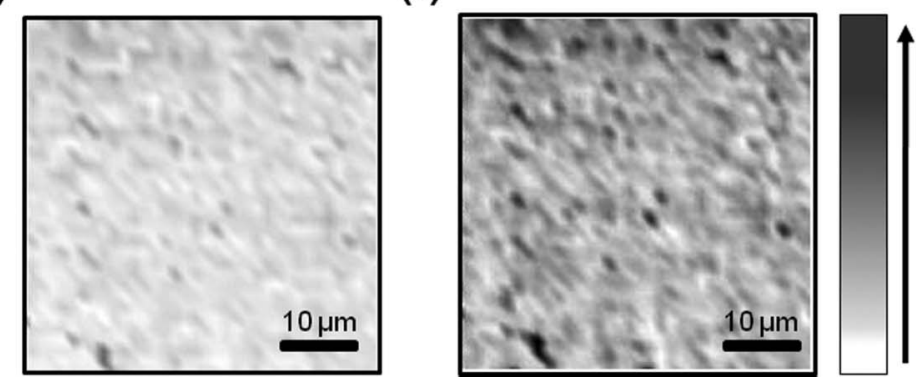

Figure 4. Imaging reflectance IR microscopy comparing $50 \mu \mathrm{m} \times 50 \mu \mathrm{m}$ images of the fluorocarbon regions (C-F stretch, $1223-1275 \mathrm{~cm}^{-1}$, panels a and d) and the hydrocarbon regions (C-H stretch, 2800-3000 $\mathrm{cm}^{-1}$, panels b and e) of the 1:14:35:50 C18/TDF/C8/TEOS xerogel following air-drying for 7 days (panels a and b) or immersion in deionized water for $48 \mathrm{~h}$ (panels $\mathrm{d}$ and e). In panels (a) and (d), lighter regions represent higher C-F stretching intensity and darker regions, lower C-F stretching intensity. In panels (b) and (e), lighter regions represent higher $\mathrm{C}-\mathrm{H}$ stretching intensity and darker regions, lower $\mathrm{C}-\mathrm{H}$ stretching intensity. In the ratio images of panels (c) and (f) relative scales were set arbitrarily to enhance contrast, darker regions represent higher $\mathrm{C}-\mathrm{F} /$ lower $\mathrm{C}-\mathrm{H}$ intensity while lighter regions represent lower $\mathrm{C}-\mathrm{F} /$ higher $\mathrm{C}-\mathrm{H}$ intensity as indicated by the intensity bar. Images pre- and post-immersion are extracted from similar areas of each slide, but are not from identical coordinates. Intensity scales are identical pre- and post-immersion.

topographically smooth when dry (Bennett et al. 2010). AFM measurements on the same series of xerogels submerged in ASW show very low surface roughness ( $0.8 \mathrm{~nm})$ and no phase segregation. Time-of-flight, secondary-ion mass spectrometry (ToF-SIMS) studies show that there is no phase segregation of fluorocarbon and hydrocarbon groups on the micrometer scale in a 25:25:50 trifluoropropyl-trimethoxysilane/C8/ TEOS xerogel (Bennett et al. 2010).

More recent studies indicate that incorporating low levels (1-2 mole- $\%$ ) of $\mathrm{C} 18$, a trialkoxysilane with a long-chain alkyl substituent, into the C8/TEOS xerogel produces topographical features on the nm- and $\mu \mathrm{m}$ scale, ie pores $c a 100-400 \mathrm{~nm}$ across and 2-7 nm deep (Gunari et al. 2011). Studies using the IR microscope with these same surfaces indicated some segregation of hydrocarbon content into micrometer-scale features (Gunari et al. 2011). These results indicate that chemical segregation in the bulk xerogel is possible and can lead to topographical features over multiple scales.

Polymers and block copolymers incorporating polyfluoroalkyl or perfluoroalkyl side chains display some phase segregation in air and undergo surface reorganization upon exposure to water (Gudipati et al. 2004; Koberstein 2004; Makal et al. 2007; Martinelli et al. 2008). Many of the morphological changes are presumed to be driven by the presence of polyethylene glycol side chains in some of these systems and surface roughness increases upon exposure to water.

The C18- and TDF-containing xerogel coatings of this study showed decreased surface roughness upon exposure to water. Both AFM (Figure 2) and IR microscopy (Figure 4) showed non-homogeneous surfaces. Prior to immersion in water, topographic AFM images of the 1:4:45:50 and the 1:14:35:50 C18/ $\mathrm{TDF} / \mathrm{C} 8 / \mathrm{TEOS}$ xerogels showed spherical ( $\mathrm{ca} 20$ $25 \mathrm{~nm}$ diameter) nanodomains that were segregated from the xerogel continuous phase (Figure 2a). Upon immersion in deionized water for $48 \mathrm{~h}$, some surface reorganization was apparent: the spherical nanodomains become less apparent (Figure 2d) and, overall, there was a significant decrease in surface roughness as shown in Figure 3. AFM phase images showed a nonhomogeneous surface with nanodomains of $c a 100$ $150 \mathrm{~nm}$ diameter prior to immersion in deionized 


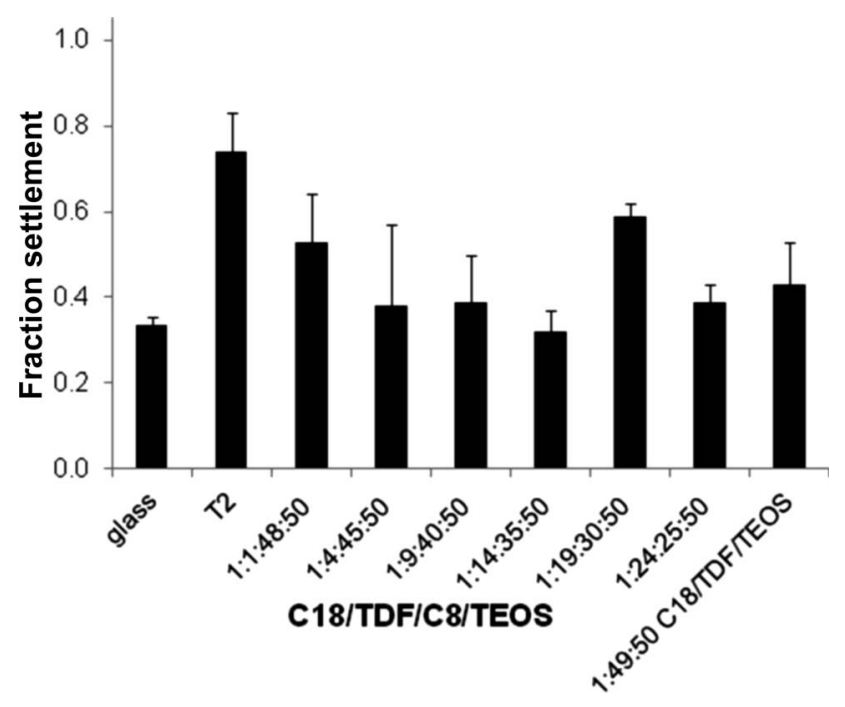

Figure 5. Settlement of barnacle cypris larvae on xerogel coatings applied to glass dishes, and glass and T2 standards. Each value is the mean from 3 replicate measurements. Error bars represent the SE of the mean.

water (Figure 2b) and much smaller domains after immersion (Figure 2e). The surface reorganization upon immersion in water (Figure 3) had minimal impact on measurable surface properties such as the surface free energy $\left(\gamma_{\mathrm{S}}\right)$ and the static water contact angle $\left(\theta_{\mathrm{Ws}}\right)$, which were relatively unchanged pre- and post-immersion over the entire range of TDF concentrations (1 to 24 mole- $\%$ ) in this study (Figure 1).

The nature of the cross-linking and functional group distribution in the xerogels differs from that of fluorinated block copolymers that undergo surface reorganization upon exposure to water (Gudipati et al. 2004; Koberstein 2004; Makal et al. 2007; Martinelli et al. 2008). Immersion in water did not change the relative intensity of the silanol bands in the surface regions shown in Figure 4 (data not shown) suggesting that further cross-linking of the surface is not responsible for the change.

The IR microscope showed some segregation of chemical functionality in the bulk xerogel on roughly the micrometer scale, which is the spatial resolution of the IR microscopy images (Figure 4). While the IR microscope does not give absolute hydrocarbon and fluorocarbon domains, micrometer-scale features characterized by either increased hydrocarbon content or increased fluorocarbon content are apparent in the "ratio" images of Figure 4 both pre- and postimmersion in water (panels $\mathrm{c}$ and $\mathrm{f}$, respectively). Immersion in water appears to have little impact on the distribution of the larger micrometer-scale, bulk features, suggesting that surface reorganization is on the nanometer-scale within the regions of higher fluorocarbon and/or hydrocarbon content.
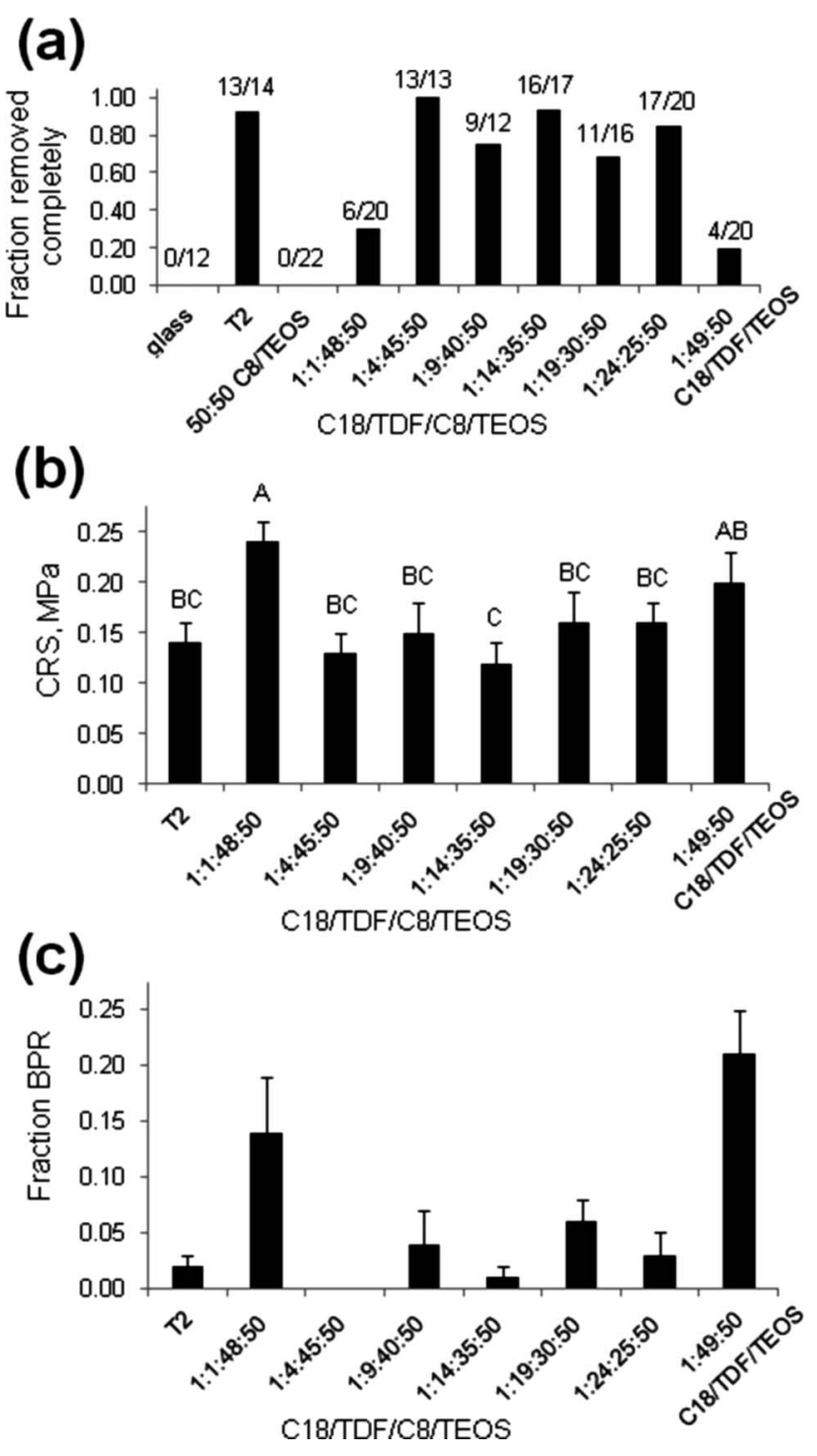

Figure 6. Fraction of juvenile barnacles removed completely via shear pressure (panel a), critical removal stress (CRS) in $\mathrm{MPa}$ for barnacles removed completely (panel b), and fraction of barnacle basal plate remaining (BPR) from those barnacles removed completely or incompletely (panel c). In panel (b), coatings that share a letter have values of CRS that are not significantly different from one another. Number of barnacles, $n$, removed completely in each group and total number of barnacles pushed given in panel (a). Error bars are the SE from the mean.

The experimental values of $\gamma_{\mathrm{S}}$ (Table 1) for the TDF-containing xerogels of this study are lower in comparison to values of $\gamma_{\mathrm{S}}$ for the C8/TEOS xerogel control surface and $\mathrm{T} 2$ standard surface and are also either below or at the low end of the $20-25 \mathrm{mN} \mathrm{m}^{-1}$ range of the "Baier curve" where minimal bioadhesion has been reported (Baier et al. 1968; Baier 1984). Materials with lower values of $\gamma_{\mathrm{S}}$ have shown increased bioadhesion. 


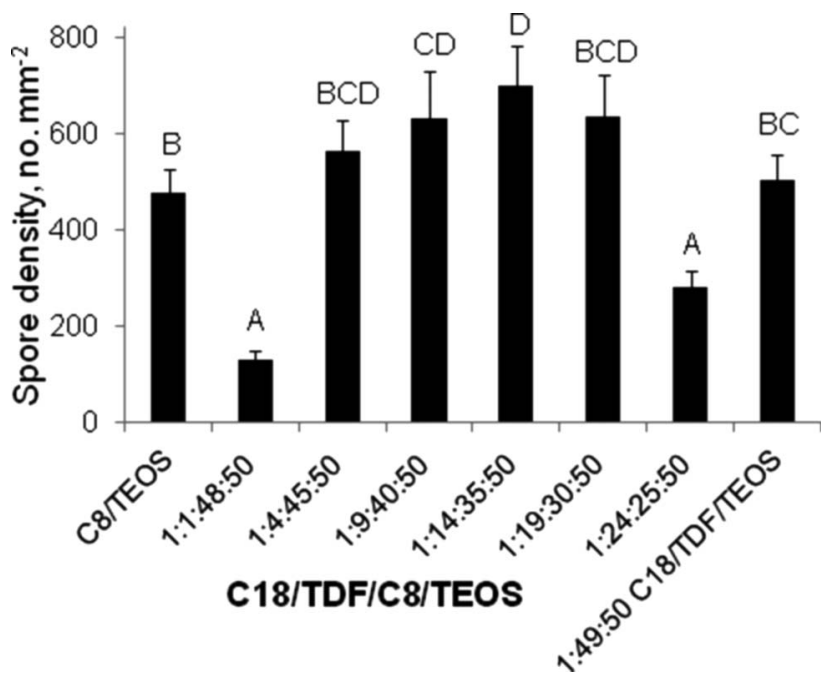

Figure 7. Settlement of zoospores of Ulva on 50:50 C8/ TEOS and TDF-containing xerogel coatings. Each value is the mean of 90 counts on each of 3 replicate slides. Error bars represent the $95 \%$ confidence limits. Coatings that share a letter have values for zoospore settlement that are not significantly different from one another.

Less than optimal performance might be expected for the lower surface energy materials as either AF or FR surfaces relative to surfaces with values of $\gamma_{S}$ in the $20-25 \mathrm{mN} \mathrm{m}^{-1}$ range of the "Baier curve" if surface energy alone were the sole determining factor. The T2 standard, for example, has $\gamma_{\mathrm{S}}$ of $23.0 \pm 0.4 \mathrm{mN} \mathrm{m}^{-1}$ (Feinberg et al. 2003), which is in the middle of the Baier minimum. In particular, the 1:4:45:50 through 1:24:25:50 C18/TDF/C8/TEOS surfaces had values of $\gamma_{\mathrm{C}}$ in the range $11.5-19.8 \mathrm{mN} \mathrm{m}^{-1}$ and values of $\gamma_{\mathrm{S}}$ in the range $16.1-21.8 \mathrm{mN} \mathrm{m}^{-1}$ and gave release of 68 $100 \%$ of juvenile barnacles. In contrast, the $50: 50 \mathrm{C} 8 /$ TEOS xerogel with $\gamma_{\mathrm{C}}$ of $21.3 \mathrm{mN} \mathrm{m}^{-1}$ and $\gamma_{\mathrm{S}}$ of 27.1 $\mathrm{mN} \mathrm{m}^{-1}$ in the middle of the Baier minimum gave $0 \%$ release of juvenile barnacles.

Settlement studies of cypris larvae of the barnacle $B$. amphitrite showed that there were no significant differences between the TDF-containing xerogel test coatings and the C8/TEOS xerogel control surface or glass and T2 standards (Figure 5). The TDF-containing and C8/TEOS xerogels and the T2 surface are all hydrophobic surfaces $\left(\theta_{\mathrm{Ws}} \geq 97^{\circ}\right)$ and the range of surface energies, which are fairly similar among these coatings $\left(\sim 10 \mathrm{mN} \mathrm{m}^{-1}\right.$ range), had no significant impact on settlement.

Settlement studies of zoospores of Ulva indicated significant differences among the C8/TEOS and TDFcontaining coatings, but these differences did not correlate with either $\theta_{\mathrm{W}_{\mathrm{s}}}$ or with $\gamma_{\mathrm{s}}$. Settlement densities on the 1:1:48:50 and 1:24:25:50 C18/TDF/ C8/TEOS xerogels were significantly lower in comparison to settlement on the C8/TEOS xerogel standard

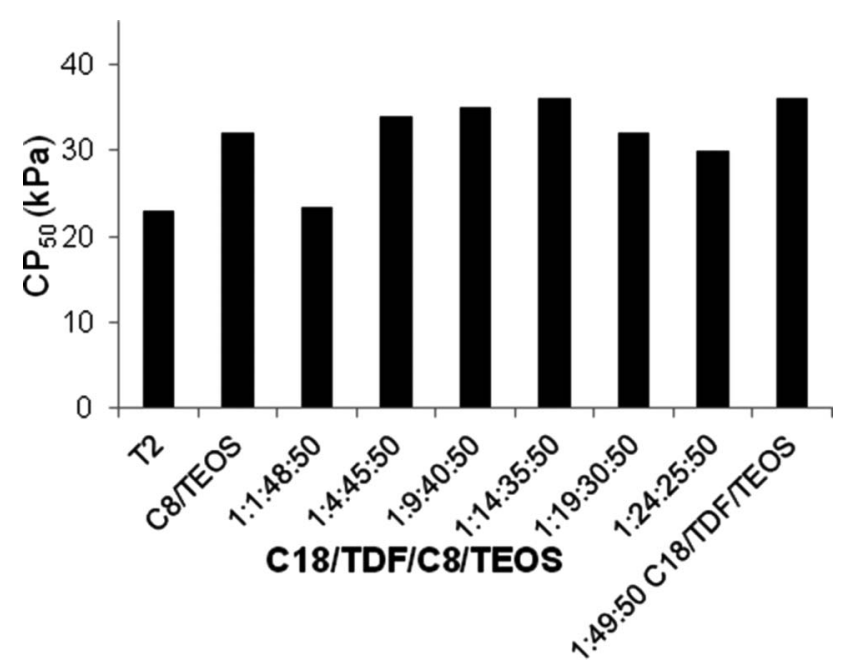

Figure 8. Critical water pressure $\left(\mathrm{CP}_{50}\right)$ to remove $50 \%$ of sporelings of Ulva from the T2 standard and the C18/TDF/ C8/TEOS and C18/TDF/TEOS xerogel coatings.

while settlement on the 1:4:45:50 C18/TDF/C8/TEOS xerogel and the C18/TDF/TEOS xerogel was not significantly different in comparison to settlement on the C8/TEOS xerogel standard. All four of these surfaces had values of $\gamma_{\mathrm{S}}\left(17.2-21.8 \mathrm{mN} \mathrm{m}^{-1}\right)$ well below that of the $\mathrm{C} 8 /$ TEOS xerogel $\left(27.1 \mathrm{mN} \mathrm{m}^{-1}\right)$. In contrast, settlement densities were highest on the 1:4:45:50, 1:9:40:50, 1:14:35:50, and 1:19:30:50 C18/ $\mathrm{TDF} / \mathrm{C} 8 /$ TEOS xerogels with values of $\gamma_{\mathrm{S}}$ in the same range. With the exception of the 1:1:48:50 C18/TDF/ C8/TEOS xerogel $\left(\theta_{\mathrm{Ws}}=410^{\circ}\right)$, all of the other xerogel surfaces including the $\mathrm{C} 8 / \mathrm{TEOS}$ xerogel had a value of $\theta_{\mathrm{Ws}}$ of $\sim 100^{\circ}$ (within experimental error). On these surfaces, settlement of zoospores does not appear to be correlated with either total surface energy or hydrophobicity.

The TDF-containing xerogel surfaces acted as FR surfaces with several comparable to the $\mathrm{T} 2$ standard with respect to release of juvenile barnacles and 7-day Ulva sporeling growth. The 1:4:45:50 and 1:14:35:50 C18/TDF/C8/TEOS xerogel surfaces and T2 standard gave essentially complete release of juvenile barnacles (Figure 6). Values of the critical removal stress (CRS) were statistically identical among these three coatings $(0.12-0.14 \mathrm{MPa})$. The remaining TDF-containing coatings also functioned as FR surfaces although not as effectively as the 1:4:45:50 and 1:14:35:50 C18/TDF/ C8/TEOS xerogel surfaces. In contrast, the C8/TEOS xerogel surface did not function as a FR surface, ie all barnacles broke before removal (Figure 6). Again, there is no direct correlation of individual coating performance with either $\gamma_{\mathrm{S}}$ or $\theta_{\mathrm{Ws}_{\mathrm{s}}}$. Values of $\mathrm{CP}_{50}$ for 7-day sporeling removal were comparable on all of the $\mathrm{C} 18 / \mathrm{TDF} / \mathrm{C} 8 / \mathrm{TEOS}$ xerogel surfaces and were 
described by a narrow range $(23.5-36 \mathrm{kPa})$, which was comparable to the T2 standard as shown in Figure 8.

The data for 7-day sporeling removal taken with the performance of the TDF-containing xerogel surfaces for removal of juvenile barnacles suggest that the 1:4:45:50 and 1:14:35:50 C18/TDF/C8/TEOS xerogels perform similarly to the T2 standard as FR surfaces. The thinner, harder xerogel surfaces may release the macrofoulers via shear rather than by peeling as might be expected with $\mathrm{T} 2$ and related silicone elastomers (Brady and Singer 2000; Berglin et al. 2003; Kim et al. 2007; Ramsay et al. 2008).

The chemical segregation of the $\mathrm{C} 18 / \mathrm{TDF} / \mathrm{C} 8 /$ TEOS xerogels of this study into nanometer- and micrometer-domains of higher fluorocarbon and hydrocarbon content likely contributes to the FR performance observed in these systems in addition to other surface properties. Nanotexture has previously been correlated with superhydrophobicity (Genzer and Efimenko 2006; Genzer and Marmur 2008) and improved $\mathrm{AF} / \mathrm{FR}$ performance of coatings has been attributed to topography at the nanoscale (eg Beigbeder et al. 2008; Akesso et al. 2009; Grozea et al. 2009; Martinelli et al. 2009; Scardino and deNys 2011). However, these systems were presumed to be chemically homogeneous. Similarly, patterned surfaces with well-defined distances between pillars, channels and bioinspired designs such as Sharklet ${ }^{\mathrm{TM}}$ have also been effective at minimizing fouling (Schumacher et al. 2007; Long et al. 2010; Magin et al. 2010). Again, these surfaces, while patterned, are chemically homogeneous. Recent data suggest that barnacle cyprids select textures to which they can adhere most strongly (Aldred et al. 2010). The hydrophobic nature of C18/ $\mathrm{TDF} / \mathrm{C} 8 / \mathrm{TEOS}$ xerogel coatings and low surface energy likely contribute to their FR behavior, as well.

Xerogel surfaces can be fine-tuned to provide surfaces with different wettability and values of $\gamma_{C}$ or $\gamma_{\mathrm{S}}$ (Tang et al. 2005; Bennett et al. 2010; Finlay et al. 2010; Gunari et al. 2011). The topography of the xerogel surfaces can also be fine-tuned by the incorporation of a long-chain alkyl component and varying amounts of the polyfluorinated TDF as shown by the xerogels of this study. The formulation and coating of these TDF-containing xerogel surfaces require no special attention or preparation (prepatterning). Depositing the xerogel by spin coating leads to self-segregation of hydrocarbon and fluorocarbon domains.

Overall, xerogel surfaces have high potential as FR or easy-clean materials with the 1:4:45:50 and 1:14:35:50 C18/TDF/C8/TEOS xerogels of this study being perhaps the most promising leads yet in xerogel surface chemistry. These coatings may be useful as AF/ FR surfaces in applications where thicker coatings are not optimal or practical. In particular, these coatings, as with other xerogel coatings, are optically transparent (Brinker and Scherer 1990; Avnir 1995; Ingersol and Bright 1997) and have applications as AF/FR coatings where optical transparency is important (marine sensors, underwater cameras, submersible solar panels).

\section{Acknowledgements}

The authors thank the Office of Naval Research for supporting this research through grants to M. E. C. and J. A. C. (award N00014-08-1-0010), D. E. W. (award N00014-09-1-0350), and F. V. B. and M. R. D. (award N0014-09-1-0217). The authors also thank Professor A.B. Brennan for providing slides coated with Silastic ${ }^{\mathbb{R}}$ T2 and Dr Anne E. Meyer (Industry/University Center for Biosurfaces and Biomaterials Graduate Program, University at Buffalo) for the comprehensive contact angle analysis measurements.

\section{References}

Akesso L, Pettitt ME, Callow JA, Callow ME, Stallard J, Teer D, Liu C, Wang S, Zhao Q, D'Souza F, et al. 2009. The potential of nano-structured silicon oxide type coatings deposited by PACVD for control of aquatic biofouling. Biofouling 25:55-67.

Aldred N, Scardino A, Cavaco A, de Nys R, Clare AS. 2010. Attachment strength is a key factor in the selection of surfaces by barnacle cyprids (Balanus amphitrite) during settlement. Biofouling 26:287-299.

Avnir D. 1995. Organic chemistry within ceramic matrices: doped sol-gel materials. Acc Chem Res 28:328-341.

Baier RE. 1984. Initial events in microbial film formation. In: Costlow JD, Tipper RC, editors. Marine biodeterioration: an interdisciplinary study. Annapolis (MD): US Naval Institute Press. p. 57-62.

Baier RE, Meyer AE. 1992. Surface analysis of foulingresistant marine coatings. Biofouling 6: 165-180.

Baier RE, Shaffin EG, Zisman WA. 1968. Adhesion: mechanisms that assist or impede it. Science 162:1360 1368.

Barlow D, Dickinson GH, Orihuela-Diaz B, Kulp J, Rittschof D, Wahl K. 2010. Functional amyloid and bio-adhesion: characterization of amyloid-like nanofibrils composing the adhesive plaque of the barnacle Balanus amphitrite. Langmuir 26:6549-6556.

Beigbeder A, Degee P, Conlan SL, Mutton RJ, Clare AS, Pettitt ME, Callow ME, Callow JA, Dubois P. 2008. Preparation and characterisation of silicone-based coatings filled with carbon nanotubes and natural sepiolite and their application as marine fouling-release coatings. Biofouling 24:291-302.

Bennett SM, Finlay JA, Gunari N, Wells DD, Meyer AE, Walker GC, Callow ME, Callow JA, Bright FV, Detty MR. 2010. The role of surface energy and water wettability in aminoalkyl/fluorocarbon/hydrocarbonmodified xerogel surfaces in the control of marine biofouling. Biofouling 26:235-246.

Berglin M, Lönn N, Gatenholm P. 2003. Coating modulus and barnacle bioadhesion. Biofouling 19 (Suppl):63-69. 
Berglin M, Larsson A, Jonsson PR, Gatenholm P. 2001. The adhesion of the barnacle, Balanus improvisus, to poly (dimethylsiloxane) fouling-release coatings and poly (methyl methacrylate) panels: the effect of barnacle size on strength and failure mode. $\mathbf{J}$ Adhesion Sci Tech 15:1485-1502.

Brady RF. 1997. In search of non-stick coatings. Chem Ind (London) 6:219-222.

Brady RF, Singer IL. 2000. Mechanical factors favoring release from fouling release coatings. Biofouling 15:7381.

Brinker CJ, Scherer GW. 1990. Sol-gel science: the physics and chemistry of sol-gel processing. New York: Academic Press. 908 pp.

Callow ME, Callow JA, Pickett-Heaps JD, Wetherbee R. 1997. Primary adhesion of Enteromorpha (Chlorophyta, Ulvales) propagules: quantitative settlement studies and video microscopy. J Phycol 33:938-947.

Callow ME, Jennings AR, Brennan AB, Seegert CE, Gibson A, Wilson L, Feinberg A, Baney R, Callow JA. 2002. Microtopographic cues for settlement of zoospores of the green fouling alga Enteromorpha. Biofouling 18:237-245.

Davis AJ. 1996. Non-toxic antifouling coatings - the defence side. IMAS 96: shipping and the environment - is compromise inevitable? London (UK): The Institute of Marine Engineers. p. 71-78.

Dickinson GH, Vega IE, Wahl KJ, Orihuela B, Beyley V, Rodriguez EN, Everett RK, Bonaventura J, Rittschof D. 2009. Barnacle cement: a polymerization model based on evolutionary concepts. J Exp Biol 212:3499-3510.

Dobretsov A, Thomason JC. 2011. The development of marine biofilms on two commercial non-biocidal coatings: a comparison between silicone and fluoropolymer technologies. Biofouling 27:869-880.

Feinberg AW, Gibson AL, Wilkerson WR, Seegert CA, Wilson LH, Zhao LC, Baney RH, Callow JA, Callow ME, Brennan AB. 2003. Investigating the energetics of bioadhesion on microengineered siloxane elastomers: characterizing the topography, mechanical properties, and surface energy and their effect on cell contact guidance. In: Clarson SJ, Fitzgerald JJ, Owen MF, Smith SD, van Dyke ME, editors. Synthesis and properties of silicones and silicone-modified materials. Am Chem Soc 838: 196-211.

Finlay JA, Fletcher BR, Callow ME, Callow JA. 2008b. Effect of background colour on growth and adhesion strength of Ulva sporelings. Biofouling 24:219-225.

Finlay JA, Callow ME, Schultz MP, Swain GW, Callow JA. 2002. Adhesion strength of settled spores of the green alga Enteromorpha. Biofouling 18:251-256.

Finlay JA, Krishnan S, Callow ME, Callow JA, Dong R, Asgill N, Wong K, Kramer EJ, Ober CK. 2008a. Settlement of Ulva zoospores on patterned fluorinated and PEGylated monolayer surfaces. Langmuir 24:503510.

Finlay JA, Bennett SM, Brewer LH, Sokolova A, Clay G, Gunari N, Meyer AE, Walker GC, Wendt DE, Callow ME, et al. 2010. Barnacle settlement and the adhesion of protein and diatom microfouling to xerogel films with varying surface energy and water wettability. Biofouling 27:657-666.

Genzer J, Efimenko K. 2006. Recent developments in superhydrophobic surfaces and their relevance to marine fouling: a review. Biofouling 22:339-360.

Genzer J, Marmur A. 2008. Biological and synthetic selfcleaning surfaces. MRS Bull 33:742-746.
Gohad NV, Shah NM, Metters AT, Mount AS. 2010. Noradrenaline deters marine invertebrate biofouling when covalently bound in polymeric coatings. J Exp Mar Biol Ecol 394:63-73.

Grozea CM, Gunari N, Finlay JA, Callow ME, Callow JA, Lu Z-H, Walker GC. 2009. Water-stable biblock polystryrene-block-Poly(2-vinyl pyridine) and diblock polystyrene-block-poly (methyl methacrylate) cylindrical patterned surface inhibit settlement of zoospores of the green alga Ulva. Biomacromolecules 10:1004-1012.

Gudipati CS, Finlay JA, Callow JA, Callow ME, Wooley KL. 2005. The antifouling and fouling-release performance of hyperbranched fluoropolymer (HBFP)-poly (ethylene glycol) (PEG) composite coatings evaluated by adsorption of biomacromolecules and the green fouling alga Ulva. Langmuir 21:3044-3053.

Gudipati CS, Greenlief CM, Johnson JA, Pornpimol P, Wooley KL. 2004. Hyperbranched fluoropolymer and linear poly(ethylene glycol) based amphiphilic crosslinked networks as efficient antifouling coatings: an insight into the surface compositions, topographies, and morphologies. J Polym Sci Pol Chem 42:6193-6208.

Gunari N, Brewer LH, Bennett SM, Sokolova A, Kraut ND, Finlay JA, Meyer AE, Walker GC, Wendt DE, Callow ME, et al. 2011. The control of marine biofouling on xerogel surfaces with nanometer-scale topography. Biofouling 27:137-149.

Ingersoll CM, Bright FV. 1997. Using sol-gel-based platforms for chemical sensors. Chemtech 27:26-35.

Kaelbe DH. 1970. Dispersion-polar surface tension properties of organic solids. J Adhesion 2:66.

Kamino K. 2010. Absence of cross-linking via transglutaminase in barnacle cement and redefinition of the cement. Biofouling 26:755-760.

Kim J, Chisholm BJ, Bahr J. 2007. Adhesion study of silicone coatings: the interaction of thickness, modulus, and shear rate on adhesion force. Biofouling 23:113-120.

Koberstein JT. 2004. Molecular design of functional polymer surfaces. J Polym Sci Pol Phys 42:2942-2956.

Lindner E. 1992. A low surface energy approach in the control of marine biofouling. Biofouling 6:193-205.

Long CJ, Schumacher JF, Robinson II PAC, Finlay JA, Callow ME, Callow JA, Brennan AB. 2010. A model that predicts the attachment behaviour of Ulva linza zoospores on surface topography. Biofouling 26:411419.

Magin CM, Long CJ, Cooper SP, Ista LK, Lopez GP, Brennan AB. 2010. Engineered antifouling microtopographies: the role of Reynolds number in a model that predicts attachment of zoospores of Ulva and cells of Cobetia marina. Biofouling 26:719-727.

Makal U, Uslu N, Wynne KJ. 2007. Water makes it hydrophobic: contraphilic wetting for polyurethanes with soft blocks having semifluorinated and 5,5-dimethylhydantoin side chains. Langmuir 23:209-216.

Marabotti I, Morelli A, Orsini LM, Martinelli E, Galli G, Chiellini E, Lien EM, Pettitt ME, Callow ME, Callow JA, et al. 2009. Fluorinated/siloxane copolymer blends for fouling release: chemical characterisation and biological evaluation with algae and barnacles. Biofouling 25:481-493.

Martinelli E, Menghetti S, Galli G, Glisenti A, Krishnan S, Paik MY, Ober CK, Smilgies D-M, Fischer DA. 2009. Surface engineering of styrene/PEGylated-fluoroalkylstyrene block copolymer thin films. J Polym Sci Pol Chem 47:267-284. 
Martinelli E, Suffredini M, Galli G, Glisenti A, Pettitt ME, Callow ME, Callow JA, Williams D, Lyall G. 2011. Amphiphilic block copolymer/poly(dimethylsiloxane) (PDMS) blends and nanocomposites for improved fouling-release. Biofouling 27:529-541.

Martinelli E, Agostini S, Galli G, Chiellini E, Glisenti A, Pettitt ME, Callow ME, Callow JA, Graf K, Bartels F. 2008. Nanostructured films of amphiphilic fluorinated block copolymers for fouling release application. Langmuir 24:13138-13147.

McMaster DM, Bennett SM, Tang Y, Finlay JA, Kowalke GL, Nedved B, Bright FV, Callow ME, Callow JA, Wendt DE, et al. 2009. Antifouling character of 'active' hybrid xerogel coatings with sequestered catalysts for the activation of hydrogen peroxide. Biofouling 25:21-33.

Nyilas E, Morton WA, Cumming RD, Lederman DM, Chiu TH, Baier RE. 1977. Effects of polymer surface molecular-structure and force-field characteristics on blood interfacial phenomena. 1. J Biomed Mat Res 11:51-68.

Owens DK, Wendt RC. 1969. Estimation of the surface free energy of polymers. J Appl Polym Sci 13:1741-1747.

Piola RF, Dafforn KA, Johnston EL. 2009. The influence of antifouling practices on marine invasions. Biofouling 25:633-644.

Ramsay DB, Dickinson GH, Orihuela B, Rittschof D, Wahl KJ. 2008. Base plate mechanics of the barnacle Balanus amphitrite (=Amphibalanus amphitrite). Biofouling 24:109-118.

Scardino AJ, deNys R. 2011. Mini-review: Biomimetic models and bioinspired surfaces for fouling control. Biofouling. 27:73-86.

Schultz MP. 2007. Effects of coating roughness and biofouling on ship resistance and powering. Biofouling $23: 331-341$
Schultz MP, Bendick JA, Holm ER, Hertel WM. 2011. Economic impact of biofouling on a naval surface ship. Biofouling 27:87-98.

Schumacher JF, Carman ML, Estes TG, Feinberg AW, Wilson LH, Callow ME, Callow JA, Finlay JA, Brennan AB. 2007. Engineered antifouling microtopographies effect of feature size, geometry, and roughness on settlement of zoospores of the green alga Ulva. Biofouling 23:55-62.

Selvaggio P, Tusa S, Detty MR, Bright FV, Ciriminna R, Pagliaro M. 2009. Ecofriendly protection from biofouling of the monitoring system at Pantelleria's Cala Gadir underwater archaeological site, Sicily. Int J Naut Arch $38: 417-421$

Starr RC, Zeikus JA. 1987. UTEX - The culture collection at the University of Texas. J Phycol 23(Suppl):S1-S27.

Tang Y, Finlay JA, Kowalke GL, Meyer AE, Bright FV, Callow ME, Callow JA, Wendt DE, Detty MR. 2005. Hybrid xerogel films as novel coatings for antifouling and fouling release. Biofouling 21:59-71.

Thomas KV, Brooks S. 2010. The environmental fate and effects of antifouling paint biocides. Biofouling 26:73-88

Weinman CJ, Finlay JA, Park D, Paik MY, Krishnan S, Sundaram HS, Dimitriou M, Sohn KE, Callow ME, Callow JA, et al. 2009. ABC triblock surface active block copolymer with grafted ethoxylated fluoroalkyl amphiphilic side chains for marine antifouling/fouling-release applications. Langmuir 25:12266-12274.

Wilker JJ. 2010. The iron-fortified adhesive system of marine mussels. Angew Chem Int Ed 49:8076-8078.

Zisman WA. 1964. Relation of the equilibrium contact angle to liquid and solid constitution. Contact angle wettability and adhesion, vol. 43. Adv Chem Ser. Washington (DC): Am Chem Soc. p. 1-51. 